\title{
Isothermal Transformations in Alkane Alloys
}

\author{
D. Mondieig* and V. Metivaud
}

Centre de Physique Moléculaire Optique et Hertzienne, UMR 5798 au CNRS-Université Bordeaux I, F-33405 Talence Cedex, France

\author{
H. A. J . Oonk
}

Chemical Thermodynamics Group, Debye Institute, Faculty of Chemistry, Utrecht University, Padualaan, 8, 3584 CD Utrecht, The Netherlands

\section{A. Cuevas-Diarte}

Departament de Cristal.lografia, Universitat de Barcel ona, Marti i Franquès, E-08028 Barcelona, Spain

Received November 19, 2002. Revised Manuscript Received March 20, 2003

\begin{abstract}
We show that it is possible to make mixed n-alkane samples to change isothermally from the ordered crystal state $\left(\Phi_{\text {ord }}\right)$ to the rotator state $R$. This isothermal transition has been observed in DSC and X-ray powder diffraction experiments, for all compositions in various binary systems, by maintaining mixed samples for a long time in the R state. Thermodynamic analysis of the isothermal data, which correspond to experimental EGC temperatures, results in a successful calculation of the $\left[\Phi_{\text {ord }}+R\right]$ equilibrium temperatures. The thermodynamic interpretation and X-ray diffraction observations show that the phenomenon corresponds to diffusionless, or martensitic transitions, in metal alloys.
\end{abstract}

\section{Introduction}

The experimental systems of our investigation are a series of binary combinations of n-alkanes $(\mathrm{CnH} 2 \mathrm{n}+2$; $\mathrm{Cn}$ for short) in the range from nonadecane (C19) to pentacosane (C25)-the individual systems being $\mathrm{C} 18$ $+\mathrm{C} 19, \mathrm{C} 19+\mathrm{C} 20, \mathrm{C} 19+\mathrm{C} 21, \mathrm{C} 20+\mathrm{C} 21$, and C23 + $\mathrm{C} 25$. The subject of the investigation is conveniently introduced by Figures $1^{1-4}$ and 2,5 phase diagrams pertaining to the system $\mathrm{C} 19+\mathrm{C} 21$, that is, $\{(1-X)$ $\mathrm{mol}$ of $\mathrm{C} 19+\mathrm{X}$ mol of $\mathrm{C} 21\}$.

All of the five diagrams shown by Figures 1 and 2 agree in that the single-phase field for the liquid state (L) is separated, by a narrow two-phase region, from a single-phase field in the central part of the diagram. The latter is for the mesostate called the rotator state $(R)$, or rather one of its forms, that is, the form RI $(\mathrm{Fmmm}, \mathrm{Z}=4)$. The rotator state is characterized by orientational disorder, such as that the molecules oscillate (as is the case for $\mathrm{RI}$ ) or rotate along their long axis. ${ }^{6,7}$ In the case of the four diagrams of Figure 1, the rotator field is separated from a field for the ("normal") solid state by a two-phase region with a minimum. After the four diagrams in Figure 1 had been published, it has been shown, by careful X-ray diffraction work, that,

* To whom correspondence may be addressed.Tel: 00 (33) 5400069 88. Fax: 00 (33) 5400066 86. E-mail: d.mondieig@ cpmoh.u-bordeauxl.fr.

(1) Mazee, W. M. Am. Chem. Soc. Div. Pet. Chem., Am. Chem. Soc. Chicago Meeting 1958, 3 (4), B-35.

(2) Würflinger, A.; Schneider, G. M. Ber. Bunsen-Ges. Phys. Chem. 1973, $77(2), 121$.

(3) Bucth, L. I.; Aleksandrova, E. A.; Kiprianova, E. N. Rev. High School Sci. Centre North Caucasus 1984, 10 pages.

(4) Maroncelli, M.; Strauss, H. L.; Snyder, R. G. J . Phys. Chem. 1985, 89, 5260. 1999.

(5) Métivaud, V. Ph.D. European Thesis, Bordeaux I University, in fact, four different solid forms make their appearance, giving rise to six single-phase fields; see Figure 2. These forms are Oi (orthorhombic, Pcam, $Z=4$ ), Odci (orthorhombic, Pnma, $Z=4$ ), Mdci (monoclinic, $A a, Z=4$ ), and $\mathrm{Op}$ (orthorhombic, $\mathrm{Pca} 2_{1}, \mathrm{Z}=4$ ). ${ }^{8}$ The four forms are referred to as the "ordered" forms, $\Phi_{\text {ord. }}$.

Passing over the fact that there is more than one $\Phi_{\text {ord }}$ form, one can observe that the five phase diagrams in Figures 1 and 2 show notable differences with regard to the width of the $\left[R+\Phi_{\text {ord }}\right]$ region. These differences are too significant to be ascribed to experimental errors, or to differences in the interpretation of thermograms. In other terms, the differences have to correspond to differences in experimental procedures, in combination with absence of full thermodynamic equilibrium. The fact is that, for a mixed crystal, the equilibrium transition from $\Phi_{\text {ord }}$ to $R$ requires a continuous redistribution of the component substances over the two different phases, $\Phi_{\text {ord }}$ and R-until the material is fully homogeneous again. In this respect the transition of a mixed crystal differs from the transition of its pure components.

From other studies it is known that, in certain cases, the diffusion of the molecules, required for full thermodynamic equilibrium, can be suppressed. And if so, the transition will proceed in a quasi-isothermal manner, resembling the transition in a pure substance. A speaking example is found in the system 1,4-dichlorobenzene + 1,4-dibromobenzene, pertaining to the melting of

(6) Sirota, E. B.; King, H. E., J r.; Singer, D. M.; Shao, H. H. J . Chem. Phys. 1993, 98 (7), 5809.

(7) Sirota, B.; King, H. E., J r.; Shao, H. H.; Singer, D. M. J . Phys. Chem. 1995, 99, 798.

(8) Rajabalee, F.; Métivaud, V.; Mondieig, D.; Haget, Y.; CuevasDiarte, M. A. J . Mater. Res. 1999, 14 (6), 2644. 


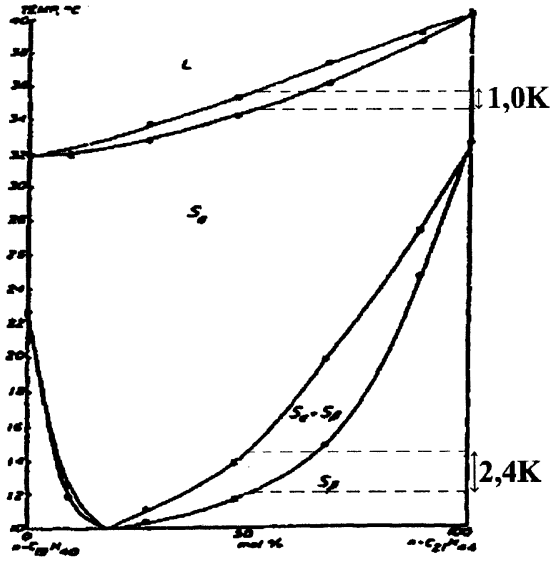

(a)

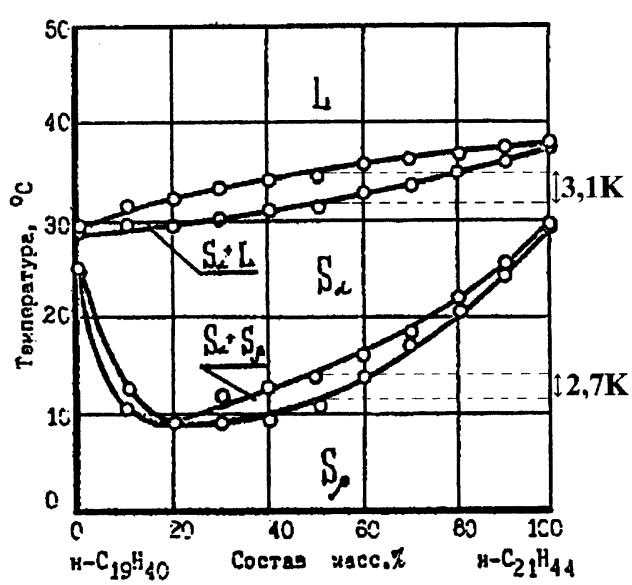

(c)

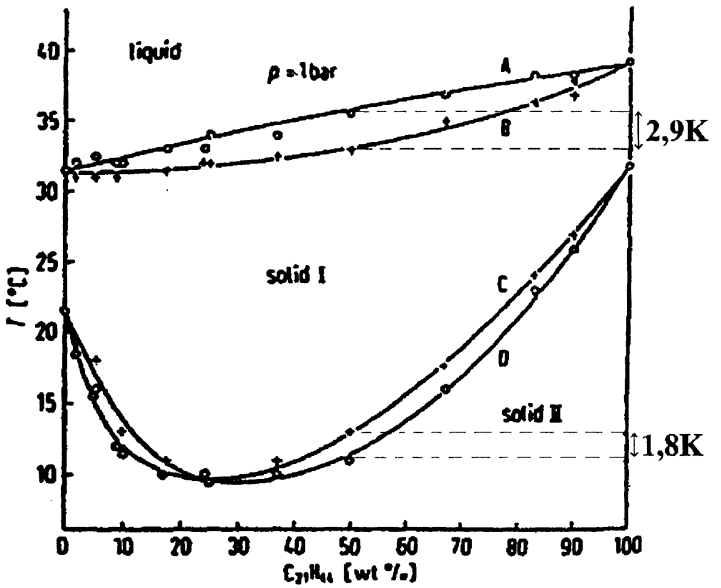

(b)

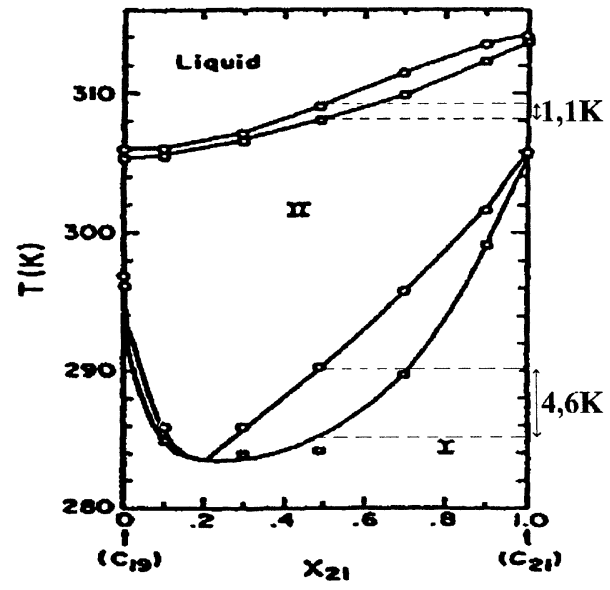

(d)

Figure 1. C19-C21 binary phase diagrams proposed by different authors: (a) by W. M. Mazee (1958); ${ }^{1}$ (b) by A. Würflinger et al. (1973); ${ }^{2}$ (c) by L. I. Boutch et al. (1984); ${ }^{3}$ (d) by Maroncelli et al. (1985). ${ }^{4}$ The above figures were adapted from their respective sources.

mixed crystalline material prepared by zone leveling. ${ }^{9}$ In physical metallurgy the terms martensitic transformations and diffusionless transformations are used (see, e.g., ref 10).

Inspired by the observations mentioned above, we decided to undertake the investigation which is reported in this paper. The aim of the investigation has been the following: (i) to search for the conditions necessary to make alkane mixed crystals to change isothermally from the $\Phi_{\text {ord }}$ to the rotator state; (ii) to subsequently use the isothermal data for a thermodynamic analysis of the change from $\Phi_{\text {ord }}$ to $R$; and (iii) to use the result of the thermodynamic analysis to pronounce upon the significance of experimental microcal orimetric observations in the case of nonisothermal changes.

\section{Materials and Experimental Methods}

Materials. The component substances, Cn, were purchased from Fluka and Aldrich. The Cn, having parity grades higher than 99\%, were used without further purification.

(9) van Genderen, A. C. G.; de Kruif, C. G.; Oonk, H. A. J . Z. Phys. Chem. Neue Fol ge 1977, 107, 167.

(10) Porter, D. A.; Easterling, K. E. Phase Transformations in Metals and Alloys; Chapman and Hall: London, 1981.
The polymorphic and transition characteristics are as foll ows. ${ }^{11,12}$

$\mathrm{C} 18$ and $\mathrm{C} 20: \mathrm{Tp} \rightarrow$ liquid

$\mathrm{C} 19$ and $\mathrm{C} 21: \mathrm{Oi} \rightarrow \mathrm{RI} \rightarrow$ liquid

C23: Oi $\rightarrow$ Odci $\rightarrow \mathrm{RV} \rightarrow \mathrm{RI} \rightarrow \mathrm{RII} \rightarrow$ liquid

$\mathrm{C} 25: \mathrm{Oi} \rightarrow$ Odci $\rightarrow \mathrm{Mdci} \rightarrow \mathrm{RV} \rightarrow \mathrm{RI} \rightarrow \mathrm{RII} \rightarrow$ liquid

where Tp (triclinic P1, Z = 1), Oi, Odci, and Mdci (see above) are ordered crystalline forms ( $\phi_{\text {ord }}$ ) and RV (monoclinic, RV $\rightarrow$ RI is a second-order transition), RI (see above), and RII ( $\mathrm{R} \overline{3} \mathrm{~m}, \mathrm{Z}=3$ ) are rotator forms.

The mixed samples used for the experiments were initially prepared by the melting-quenching method: the homogeneous melt is quenched into liquid nitrogen.

Calorimetric Measurements. Calorimetric measurements were carried out using a Perkin-EImer DSC 7 differential scanning calorimeter under nitrogen flux. Transition characteristics-temperatures and heat effects-were determined by applying a heating rate of 2

(11) Espeau, P.; Roblès, L.; Mondieig, D.; Haget, Y .; Cuevas-Diarte, M. A.; Oonk, H. A. J . J . Chim. Phys. 1996, 93, 1217.

(12) Robles, L.; Mondieig, D.; Haget, Y.; Cuevas-Diarte, M. A. J Chim. Phys. 1998, 95, 92. 


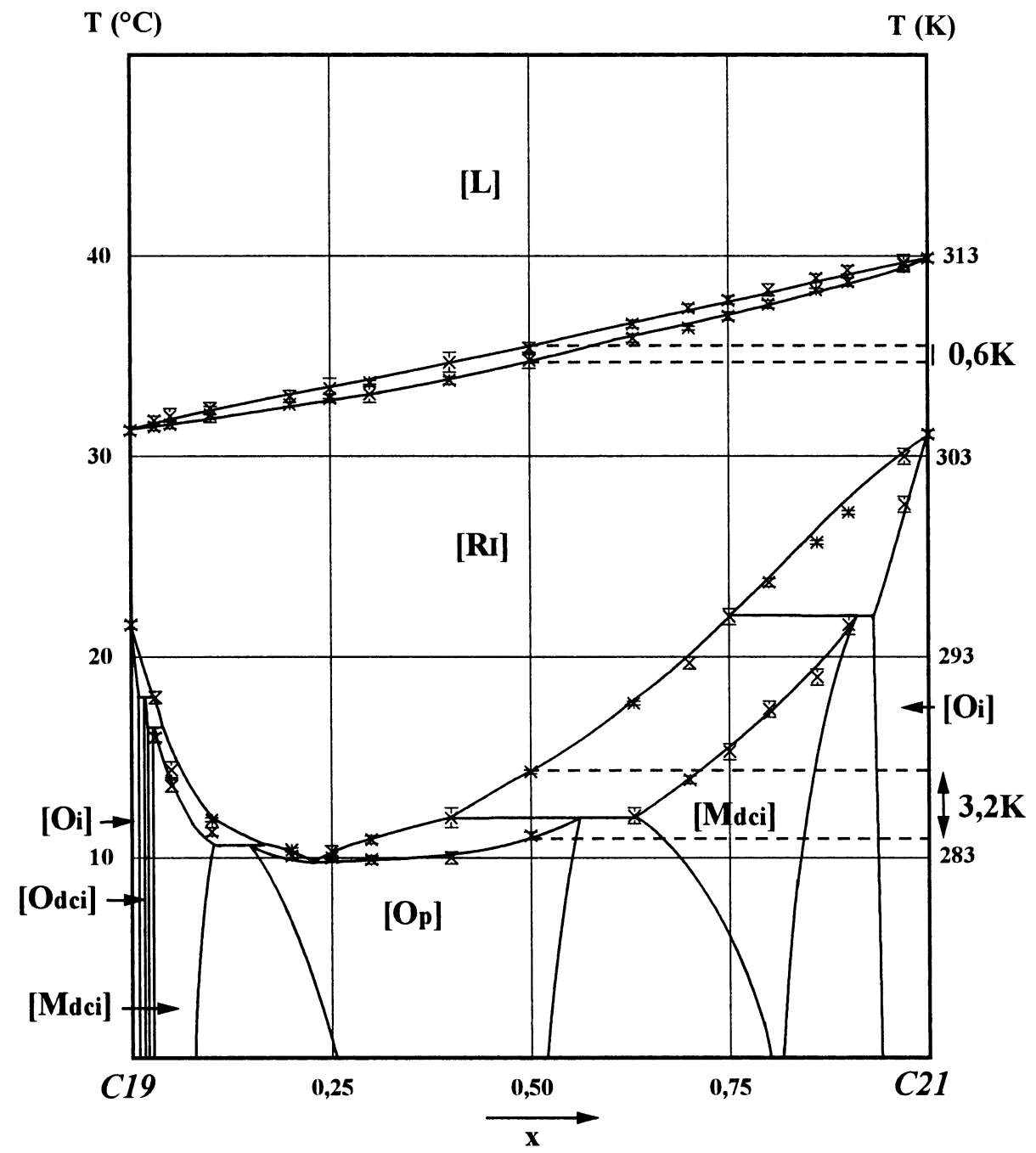

Figure 2. Our proposition for the C19-C21 phase diagram by V. Métivaud (1999). ${ }^{5}$

$\mathrm{K} \cdot \mathrm{min}^{-1}$ to samples having a mass of $(4.0 \pm 0.1) \mathrm{mg}$. The shape-factor method ${ }^{13}$ was used to correct for the intrinsic temperature lag of the technique. The random part of the uncertainties was estimated using Student's method with $95 \%$ of threshold reliability.

X-ray Diffraction. I sothermal X-ray diffraction analysis with Cu K $\alpha$ radiation ( $\lambda=1.5406 \AA$ ) were performed, on the following: (i) a Siemens D500 vertical powder diffractometer which operates in the reflection mode. Data were collected, on samples having a mass of about $5 \mathrm{~g}$, with $2 \theta$ steps of $0.04^{\circ}$ and with an interval time of $5 \mathrm{~s}$. A thin plate of glass was placed between the sample to be analyzed and the sample holder, to avoid the reflections of copper and nickel which disturb the analysis of the diffraction patterns; (ii) an INEL CPS 120 diffractometer which operates in the transmission mode. Samples, having a mass of about $3 \mathrm{mg}$, were sealed in Lindemann capillaries (diameter $=0.5 \mathrm{~mm}$ ).

\section{Experiments and Observations}

To start with, three different types of thermal treatment were carried out on mixed samples, which were subsequently studied by DSC in the temperature range

(13) Courchinoux, R.; Chanh, N. B.; Haget, Y.; Calvet, T.; Estop, E.; Cuevas-Diarte, M. A. J . Chim. Phys. 1989, 86 (3), 561. of the $\Phi_{\text {ord }} \rightarrow$ R transition: (a) Mixed samples were analyzed immediately after the quench (see above). (b) After quenching, the mixed samples were kept at a temperature corresponding to the $\Phi_{\text {ord }}$ state and then analyzed: to study the influence of the duration of the isothermal arrest. (c) After quenching, the samples first were kept at a temperature corresponding to the R state, thereafter cooled to the $\Phi_{\text {ord }}$ state, and subsequently analyzed: to study the influence of the duration of the isothermal arrest in the R state.

The experiments of type (a) and type (b) gave rise to similar DSC curves; it implies that the duration of the arrest in $\Phi_{\text {ord }}$ has no clear influence on the thermal behavior after the arrest. The experiments of type (c), on the other hand, revealed that the arrest in the rotator state procures significant changes. The evolution of the DSC signals is shown in Figure 3, and it corresponds to $\mathrm{C} 19+\mathrm{C} 21$ mixed samples held at $305 \mathrm{~K}$. The evolution of the signals is such that the signals become increasingly sharp. Additional information about the evolution with time is given in Table 1, again pertaining to the system $\mathrm{C} 19+\mathrm{C} 21$. In the table the peak characteristics and the heat effects of the transition are compared for the type (a) results and the type (c) results for an arrest in the rotator state of 16 months. The peak 

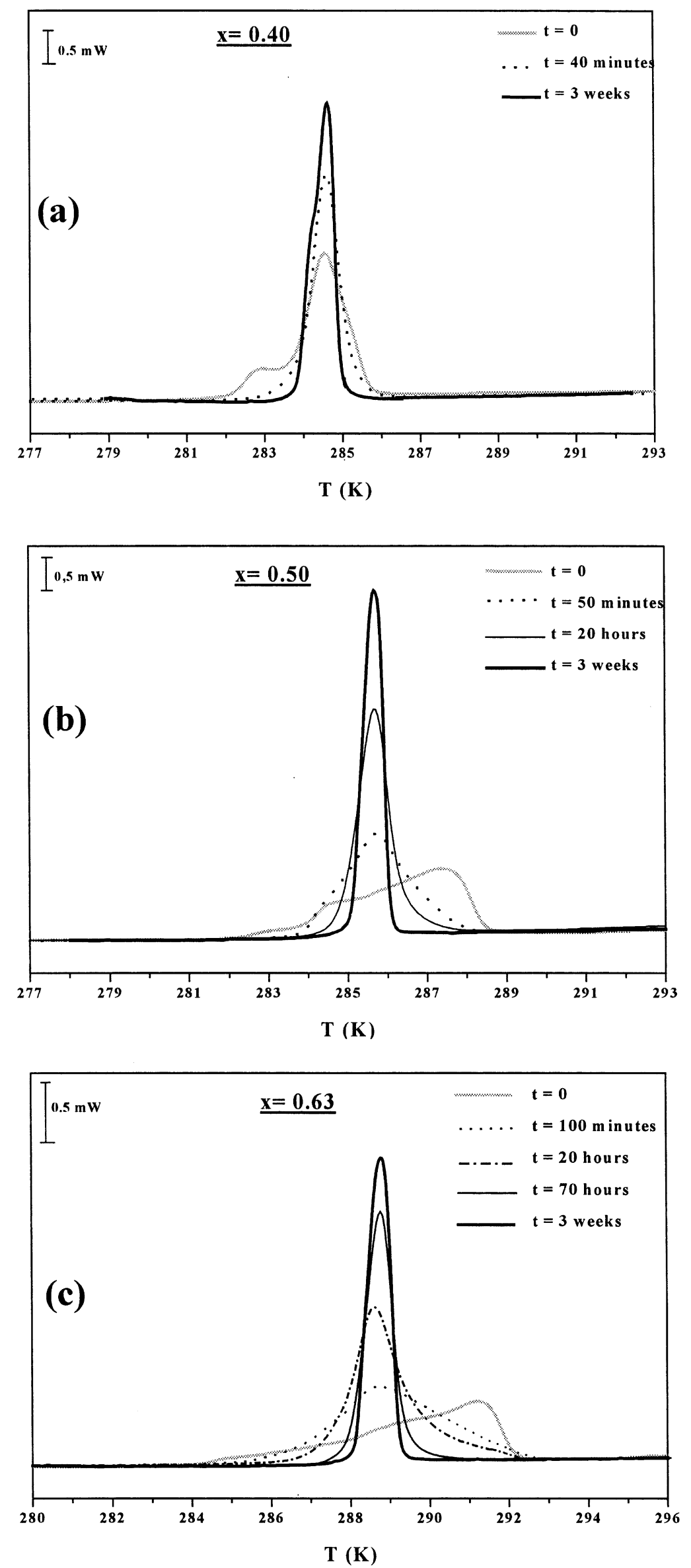

Figure 3. Evolution of the DSC signals of $\mathrm{C} 19+\mathrm{C} 21$ mixed samples with the duration of the arrest in the rotator state (mixed samples were held at $305 \mathrm{~K}$ ). (a) $\mathrm{x}_{\mathrm{C} 21}=0.40$; (b) $\mathrm{x}_{\mathrm{C} 21}=0.50$; (c) $\mathrm{x}_{\mathrm{C} 21}=0.63$. 


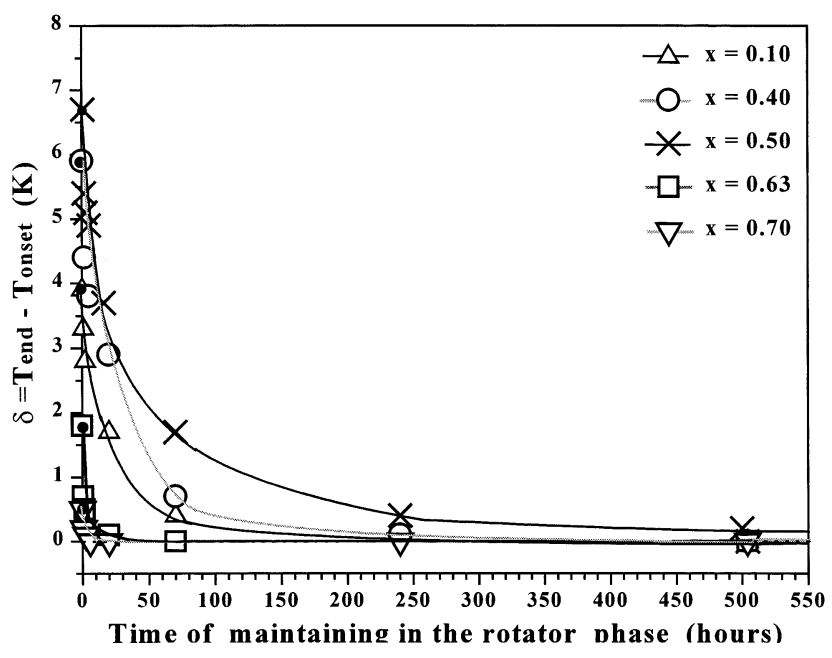

Figure 4. Evolution of the $\Phi_{\text {ord }}$ to $\mathrm{R}$ temperature range $\delta$ as a function of the duration of the arrest in the rotator state for various C19 + C21 mixed samples. ( $\delta=\mathrm{T}_{\text {end }}-\mathrm{T}_{\text {onset; }} \mathrm{T}_{\text {onset }}$ and $T_{\text {end }}$ are the onset temperature and the temperature of the end of the $\Phi_{\text {ord }}$ to $R$ transition, respectively; $T_{\text {end }}$ is obtained by using the shape factor method ${ }^{13}$ ).

\begin{tabular}{|c|c|c|c|c|c|c|c|}
\hline \multirow[b]{2}{*}{$x_{C 21}$} & \multicolumn{4}{|c|}{$t=0$} & \multicolumn{3}{|c|}{$\mathrm{t}=16$ months } \\
\hline & $\begin{array}{c}T_{\text {onset }} \\
(\mathrm{K})\end{array}$ & $\begin{array}{l}T_{\text {end }} \\
(\mathrm{K})\end{array}$ & $\begin{array}{c}\delta \\
(\mathrm{K})\end{array}$ & $\begin{array}{c}\Delta_{\text {由ord }}^{\mathrm{R}} \mathrm{H} \\
\left(\mathrm{kJ} \mathrm{mol}^{-1}\right)\end{array}$ & $\begin{array}{l}T_{\text {onset }} \\
(K)\end{array}$ & $\begin{array}{c}\delta \\
(\mathrm{K})\end{array}$ & $\begin{array}{c}\Delta_{\text {कord }}^{\mathrm{R}} \mathrm{H} \\
\left(\mathrm{kJ} \mathrm{mol}^{-1}\right)\end{array}$ \\
\hline 0.05 & 286.8 & 287.6 & 0.8 & 7.3 & 286.9 & 0 & 7.2 \\
\hline 0.10 & 284.5 & 285.1 & 0.6 & 6.7 & 284.7 & 0 & 6.9 \\
\hline 0.20 & 283.3 & 283.6 & 0.3 & 6.6 & 283.4 & 0 & 6.4 \\
\hline 0.25 & 283.2 & 283.5 & 0.3 & 6.3 & 283.0 & 0 & 6.3 \\
\hline 0.30 & 283.1 & 284.1 & 1.0 & 6.3 & 283.5 & 0 & 6.2 \\
\hline 0.40 & 283.2 & 285.2 & 2.0 & 6.6 & 283.8 & 0 & 6.4 \\
\hline 0.50 & 284.3 & 287.5 & 3.2 & 6.7 & 285.0 & 0 & 6.3 \\
\hline 0.63 & 285.3 & 290.9 & 5.6 & 7.0 & 288.1 & 0 & 7.2 \\
\hline 0.70 & 287.1 & 292.9 & 5.8 & 7.3 & 290.4 & 0 & 7.1 \\
\hline 0.75 & 288.5 & 295.2 & 6.7 & 7.9 & 291.4 & 0 & 8.2 \\
\hline 0.80 & 290.6 & 296.9 & 6.3 & 7.5 & 293.9 & 0 & 7.9 \\
\hline 0.90 & 294.8 & 300.4 & 5.6 & 9.1 & 297.8 & 0 & 8.5 \\
\hline
\end{tabular}

characteristics are the onset temperature $\left(T_{\text {onset }}\right)$, the (corrected by using the shape factor method ${ }^{13}$ ) end temperature $\mathrm{T}_{\text {end }}$, and their difference $\delta=\mathrm{T}_{\text {end }}-\mathrm{T}_{\text {onset }}$. As follows from the table, after the arrest of 16 months the value of $\delta$ invariably is zero: the change from $\Phi_{\text {ord }}$ to $\mathrm{R}$ has become an isothermal event. It also follows from the data that the temperature of the isothermal event is about halfway between the onset and end temperatures of the $\mathrm{t}=0$ signals. The $\mathrm{C} 19+\mathrm{C} 21$ system's evolution of $\delta$ with time is shown in Figure 4. The heat effect of the transition, apparently, remains unchanged.

DSC experiments carried out on mixed samples in the systems C18 + C19, C19+ C20, C20 + C21, and C23 + C25 invariably showed the same behavior as the mixed samples in the system C19 + C21. The similarity in behavior follows from Figure 5, for C19 + C21, for C18 $+\mathrm{C} 19, \mathrm{C} 19+\mathrm{C} 20$, and C20 + C21.

In a subsequent series of experiments, $X$-ray diffraction was applied to study the effect of thermal treatment on the simultaneous occurrence of two different $\Phi_{\text {ord }}$ forms. For reasons of experimental convenience, the diffraction experiments were carried out on mixed samples in the system C23 + C25: at room temperature the system is in the $\Phi_{\text {ord }}$ state, no matter its composition. The phase diagram of the system is shown in Figure 6; the experimental diagram and its thermodynamic analysis have been published before ${ }^{8,14}$

First of all, a set of three (partial) diffraction patterns are displayed in Figure 7: to underline the relatively small differences between the forms Mdci and Op and to show the evidence on which the conclusion of simultaneous occurrence is based. The diffraction patterns were recorded immediately after quenching, on samples of composition $\mathrm{X}=0.4$ (according to the phase diagram one phase, which is $\mathrm{Op}$ ), $X=0.5$ (two phases, Op and $M d c i$ ), and $X=0.8$ (one phase, $M d c i$ ).

The diffraction patterns displayed in Figure 8 show, for the mixture of equimolar composition ( $X=0.5)$, the influence of the duration of the isothermal arrest in the rotator state of $320 \mathrm{~K}$, on the simultaneous occurrence of Op and Mdci. From the figures it follows that the intensities of the Op reflections have increased and those of the Mdci reflections decreased. The same type of experiments have been carried out on mixed samples of composition $X=0.7$. The results, which are not shown here, were the same as for the mixtures of composition $X=0.5$, be it that for the $X=0.7$ mixture the intensities of the Mdci reflections had increased while those of the Op reflections had decreased.

The X-ray experiments, to study the simultaneous occurrence of two $\Phi_{\text {ord }}$ forms, were completed by a series of experiments in which the influence of the duration in $\Phi_{\text {ord }}$ was studied. It appeared that samples, which had become homogeneous, became heterogeneous againover a period of time considerably longer than needed for becoming homogeneous.

\section{Discussion (Thermodynamic Interpretation)}

When compared with the transition behavior of a pure substance, the behavior of mixed crystalline material displays pronounced similarities and obvious differences. In a heating experiment, a pure substance's transition is a quasi instantaneous phenomenon, rather independent of the experimental procedures, and at a fixed temperature. It is some kind of an intrinsic property, and this property is conserved when the substance is alloyed with another substance. It means that, whatever the experimental procedure, the transition in a binary system will take place around a curve in the TX plane, starting from the transition temperature of the first component $\left(T_{A}^{\circ}\right)$ and ending at the transition temperature of the second component $\left(T_{B}^{\circ}\right)$. The principal difference between the transitions of a pure substance and an alloy is that, for the latter, strict thermodynamic equilibrium demands a continuous redistribution of matter. The redistribution of matter is a process that takes place on another time scale than the transition from one state to the other, a process, moreover, which is sensitive to external influences, that is to say, sample handling, and way of doing experiments.

(14) Rajabalee, F.; Métivaud, V.; Oonk, H. A. J .; Mondieig, D.; Haget, Y. Chem. Mater. 1999, 10 (11), 2788. 

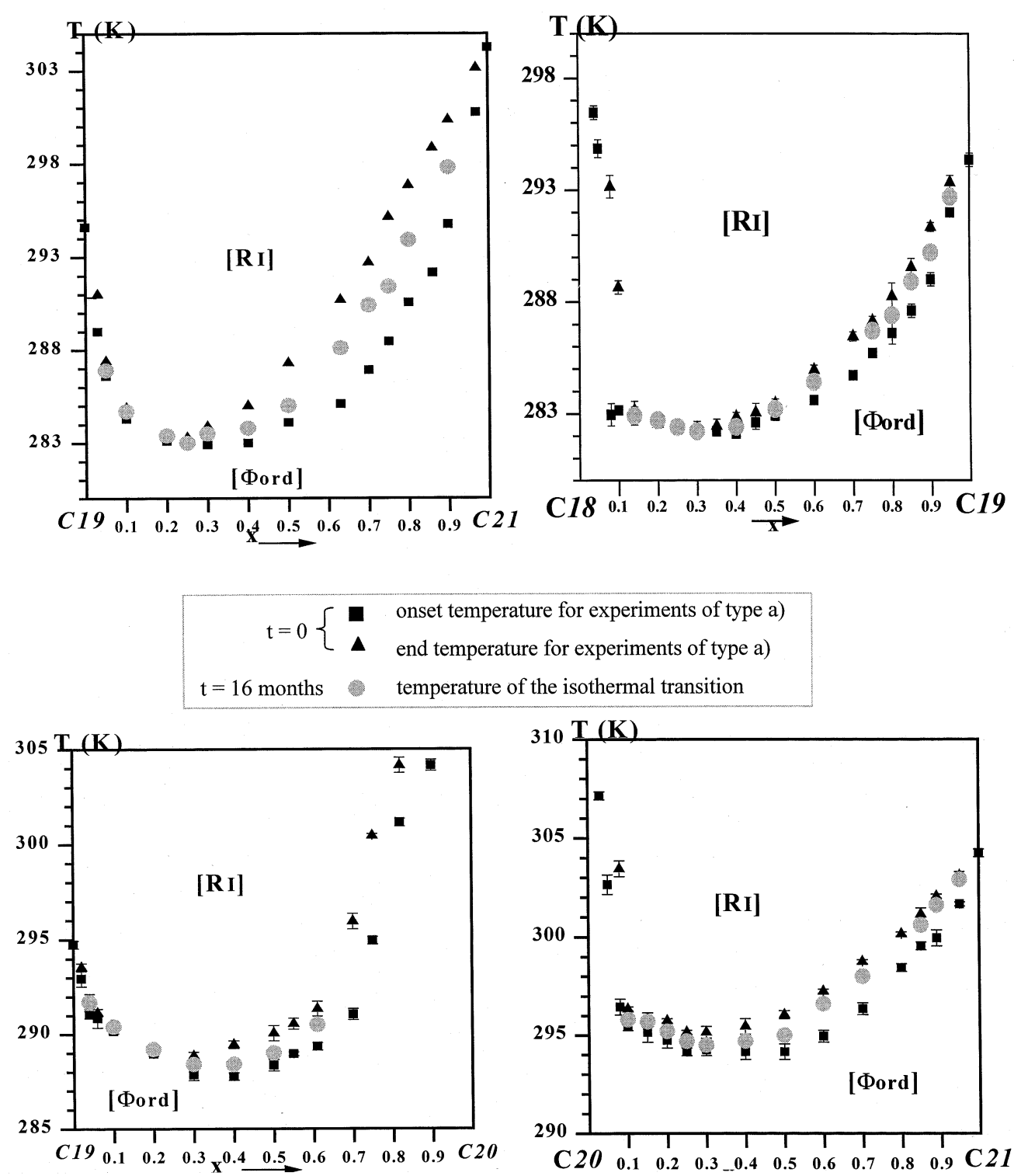

ature for experiments of type a)
of the isothermal transition

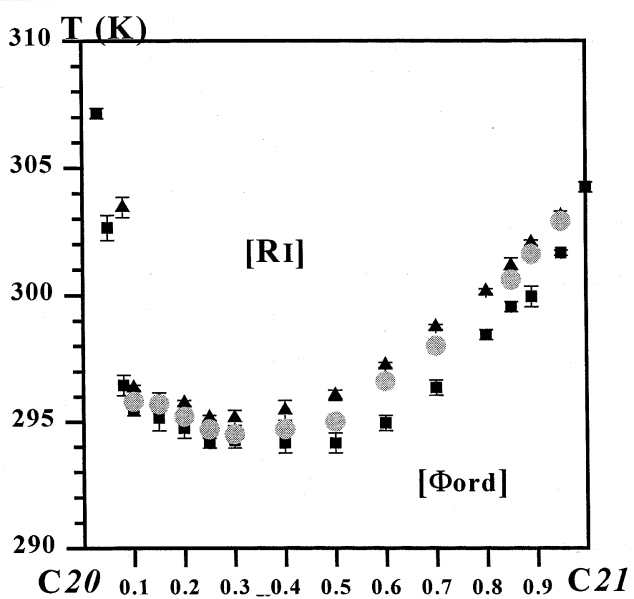

Figure 5. $\Phi_{\text {ord }} \rightarrow \mathrm{R}$ transition temperatures according to the duration of the arrest in the rotator state for the C19 + C21, C18 $+\mathrm{C} 19, \mathrm{C} 19+\mathrm{C} 20$, and C20 + C21 systems.

From the experimental observations it follows that the external influences can be such that the mixed material is made to behave like a pure substancechanging from one state to the other, isothermally and at a fixed temperature, in a diffusionless process. In terms of equilibrium thermodynamics it means that the two conditions of equality of chemical potentials

$$
\mu_{\mathrm{A}}^{\alpha}=\mu_{\mathrm{A}}^{\beta} ; \mu_{\mathrm{B}}^{\alpha}=\mu_{\mathrm{B}}^{\beta}
$$

are replaced by the condition of equality of Gibbs energies,

$$
\mathrm{G}^{\alpha}=\mathrm{G}^{\beta}
$$

where $\mathrm{A}$ and $\mathrm{B}$ are the components of the system and $\alpha$ and $\beta$ are equivalent to Mdci (or Op) and RI.

In a TX phase diagram the solution of the two equations (1) corresponds to the upper solvus and the lower solvus, that is, the boundaries of the $[\alpha+\beta]$ twophase region. In the TX plane, the solution of eq 2 is the equal-G curve (EGC), ${ }^{15}$ a curve which invariably is situated between the two solvi. The EGC is given by the following equation,

$$
\mathrm{T}_{\mathrm{EGC}}(\mathrm{X})=\frac{(1-\mathrm{X}) \Delta_{\alpha}^{\beta} \mathrm{H}_{\mathrm{A}}^{*}+\mathrm{X} \Delta_{\alpha}^{\beta} \mathrm{H}_{\mathrm{B}}^{*}+\Delta_{\alpha}^{\beta} \mathrm{G}^{\mathrm{E}}(\mathrm{X})}{(1-\mathrm{X}) \Delta \mathrm{H}_{\mathrm{A}}^{*} \mathrm{~T}_{\mathrm{A}}^{\circ}+\mathrm{X} \Delta \mathrm{H}_{\mathrm{B}}^{*} \mathrm{~T}_{\mathrm{B}}^{\circ}}
$$

where $\Delta_{\alpha}^{\beta} \mathrm{H}^{*}$ stands for the heat effect of the transition from $\alpha$ to $\beta$ and $\Delta_{\alpha}^{\beta} \mathrm{G}^{\mathrm{E}}$ for the difference in excess Gibbs energy.

For a numerical thermodynamic assessment of the observations made in this investigation, eq 3 is a convenient starting point. This is especially so because the temperatures of the isothermal changes-read the EGC temperatures-have, out of the observed temperatures, the highest accuracy. As a first step, the experimental EGC data are used to calculate, by means

(15) Oonk, H. A. J . Phase Theory: The Thermodynamics of Heterogeneous Equilibria; Elsevier Science Publishers: Amsterdam, 1981. 


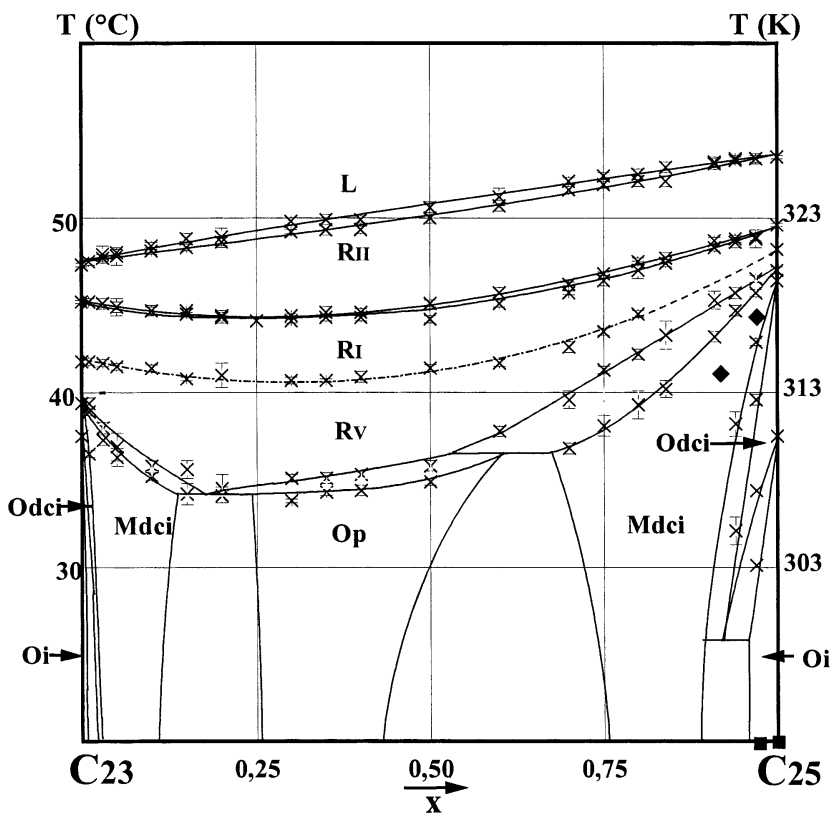

Figure 6. C23-C25 phase diagram..$^{8,14}$

of eq 3 , the function $\Delta_{\alpha}^{\beta} \mathrm{G}^{\mathrm{E}}$. In the present case $\beta$ is a rotator form, for which the excess Gibbs energy is al ready known. ${ }^{16,17}$ The excess Gibbs energy of $\alpha$, which is one of the $\Phi_{\text {ord }}$ is subsequently calculated from $\Delta_{\alpha}^{\beta} \mathrm{G}^{\mathrm{E}}$ and $\mathrm{G}^{\mathrm{E} \beta}$. Finally, the individual $\mathrm{G}^{\mathrm{E} \alpha}$ and $\mathrm{G}^{\mathrm{E} \beta}$ are used, al ong with the transition data of the components $A$ and $B$, to calculate the equilibrium phase diagram, that is to say, the upper solvus and lower one.

As an example of the sketched approach of data assessment, we give the results for the system C19+ C21, for $\alpha=$ Mdci and $\beta=\mathrm{RI}$. To begin with, it should be observed that the pure component properties in eq 3, that is, $\mathrm{T}_{\mathrm{A}}^{\circ}, \mathrm{T}_{\mathrm{B}}^{\circ}, \Delta \mathrm{H}_{\mathrm{A}}^{*}$ and $\Delta \mathrm{H}_{\mathrm{B}}^{*}$, are not known in a direct manner (for the pure components the form M dci is a metastable one, the stable transition being from Oi to $\mathrm{RI}$ ). In recent publications, ${ }^{14,18,19}$ we have suggested that the pure $\mathrm{Cn}$ transition temperatures be given by
$\mathrm{T}_{\mathrm{Cn}}^{\circ}(\mathrm{Mdci} \rightarrow \mathrm{R})=\left(103.05+13.754 \mathrm{n}-0.2033 \mathrm{n}^{2}\right) \underset{(4)}{\mathrm{K}}$

and the transition enthalpies by

$$
\Delta_{\alpha}^{\beta} \mathrm{H}_{\mathrm{Cn}}^{*}=\left(5.44-0.462 \mathrm{n}+0.0462 \mathrm{n}^{2}\right) \mathrm{kJ} \mathrm{mol}^{-1}
$$

For the calculations we have used the numerical values generated by these formulas (with the exception, however, of $\mathrm{T}_{A}^{\circ}$ in the case of the system C19 + C21, which was set at $289.0 \mathrm{~K}$; this choice, instead of 291.0 $\mathrm{K}$, improves the agreement at the left-hand side of the diagram, leaving the right-hand side virtually unchanged). The number of six EGC points $(X=0.05, T$ $=286.9 \mathrm{~K} ; 0.10,284.7 \mathrm{~K} ; 0.63,288.1 \mathrm{~K} ; 0.70,290.4 \mathrm{~K}$; $0.75,291.4 \mathrm{~K} ; 0.80,293.9 \mathrm{~K})$ were taken to calculate, eq 3 , the values of $\Delta_{\alpha}^{\beta} \mathrm{G}^{\mathrm{E}}$. These $\Delta_{\alpha}^{\beta} \mathrm{G}^{\mathrm{E}}$ values are reproduced by

$$
\begin{aligned}
\left|\Delta G^{\mathrm{E}}\right|=\{2300 X(1-X)+600 X(1-X)(1- \\
2 X)\} \mathrm{J} \mathrm{mol}^{-1}
\end{aligned}
$$

The excess Gibbs energy of the mixed rotator state is given by

$$
\begin{aligned}
& G^{E, R}=\{832 X(1-X)+217 X(1-X)(1- \\
& \text { 2X)\} } \mathrm{J} \mathrm{mol}^{-1}
\end{aligned}
$$

and, from eqs 6 and 7, it follows that the excess Gibbs energy of the mixed crystals in the form Mdci is given by

$$
\begin{array}{r}
\mathrm{G}^{\mathrm{E}, \mathrm{Mdci}}=[3132 \mathrm{X}(1-\mathrm{X})+817 \mathrm{X}(1-\mathrm{X})(1- \\
2 \mathrm{X})] \mathrm{j} \mathrm{mol}^{-1}
\end{array}
$$

The numerical values in eq 7 have been obtained as follows. Generally, the excess Gibbs energies of binary mixed crystals conform to the formula

$$
G^{E}(T, X)=A X(1-X)(1-(T / \theta))[1+B(1-2 X)]
$$

having three adjustable parameters $\mathrm{A}$ (in $\mathrm{J} \mathrm{mol}^{-1}$ ), $\theta$

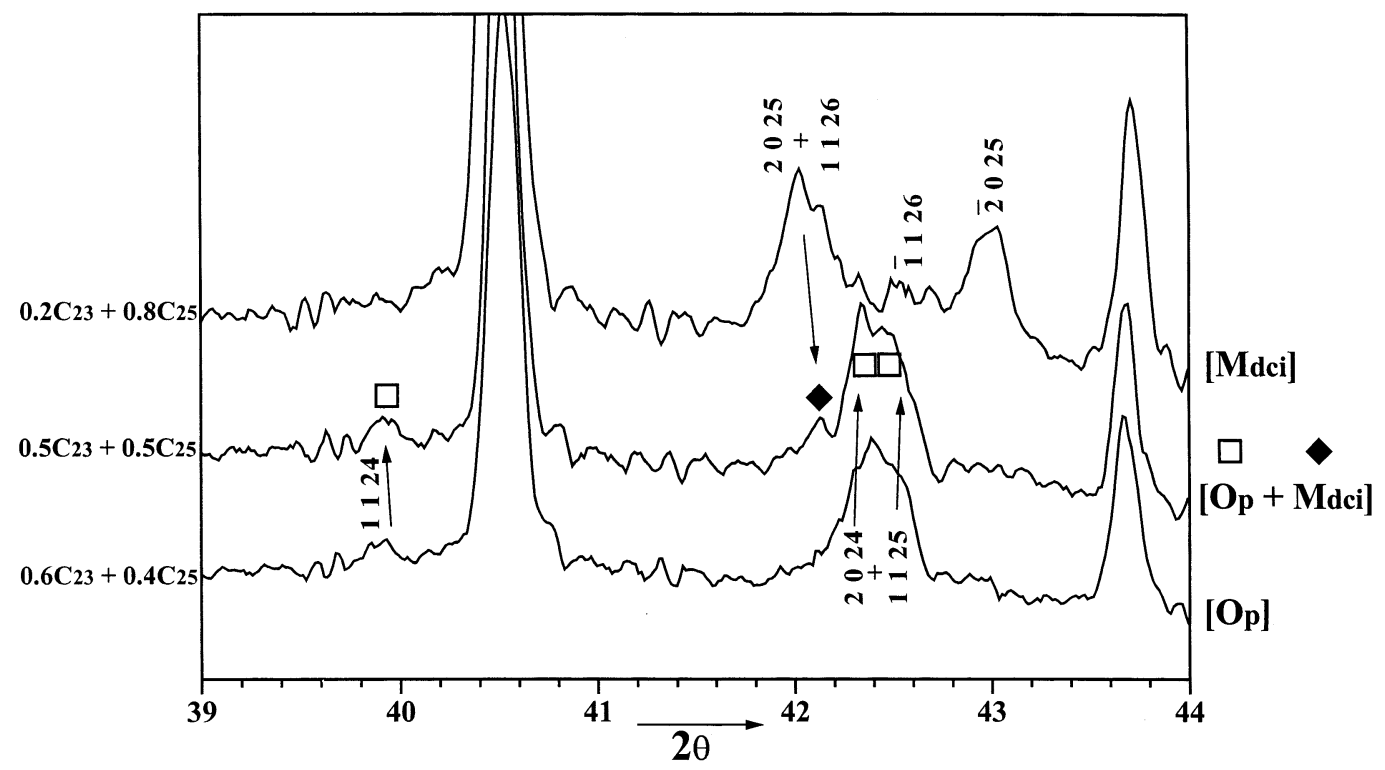

Figure 7. Diffraction patterns (in the $39^{\circ}$ to $44^{\circ} 2 \theta$ range) of C23-C25 mixed samples recorded immediately after quenching at room temperature $(\square$, Op reflection symbol; $\bullet$, Mdci reflection symbol). 


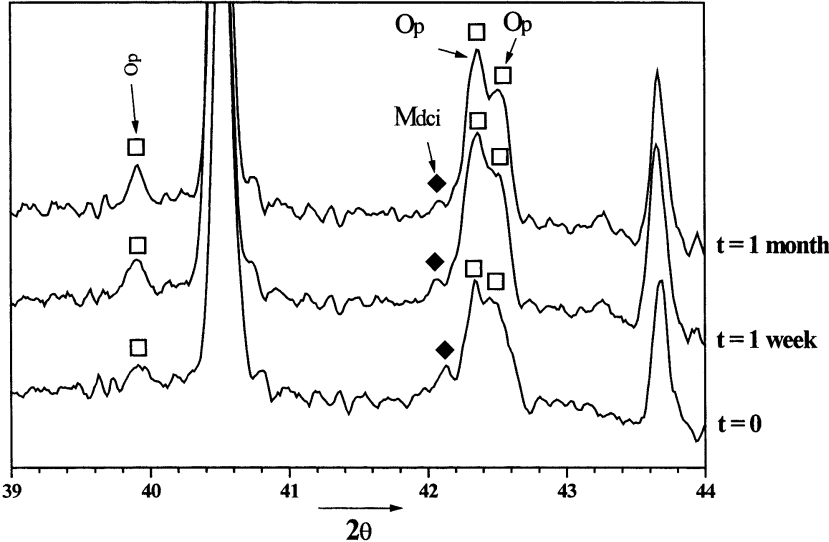

Figure 8. Influence of the duration of the isothermal arrest in the rotator state (at $320 \mathrm{~K}$ ) on the simultaneous occurrence of Op and Mdci phases: diffraction patterns (in the $39^{\circ}-44^{\circ}$ $2 \theta$ range) of the equimolar composition C23-C25 mixed sample recorded at room temperature after isothermal arrest in the rotator state $(t=0$ : no isothermal arrest; $t=1$ week and $\mathrm{t}=1$ month).

(in $\mathrm{K}$ ), and $\mathrm{B}$ (dimensionless), and referred to as the $\mathrm{AB} \theta$ formula, or model. ${ }^{16,17} \mathrm{~F}$ or the family of binary mixed crystals of which the components are n-al kanes and the form RI, the parameter $\theta$ has a common, systemindependent value of $320 \mathrm{~K}$. The parameter $\mathrm{A}$, on the other hand, is system-dependent, and such that its value is related to the relative difference in chain length between the molecules of the two components of thesystem $\mathrm{Cn}+\mathrm{Cn}^{\prime}$. The relationship is ${ }^{19}$

$$
A^{R}=\left[51.09\left(\frac{\Delta n}{\bar{n}}\right)+376.5\left(\frac{\Delta n}{\bar{n}}\right)^{2}\right] \mathrm{kJ} \mathrm{mol}{ }^{-1}
$$

where $\Delta n=\left|\left(n^{\prime}-n\right)\right|$ and $\bar{n}=(1 / 2)\left(n+n^{\prime}\right)$

With eq 10 , and putting, in eq $9, T=290 \mathrm{~K}$ (i.e., the mean temperature of the transition range), and, moreover, taking for the parameter $\mathrm{B}$ the ratio of the two numerical values in eq 6 (i.e., $B=6 / 23$ ), eq 7 is obtained.

The phase diagram generated by the thermodynamic transition properties of the two components, C19 and C21, along with the excess functions of the two mixed states, eqs 7 and 8, is shown in Figure 9. The diagram, Figure 9, is an example of a coherent overall result, in that, for the experiments of type (a), the onset and end temperatures of the peaks virtually coincide with the calculated solvi. The mean of the absolute differences between calculated and experimental temperatures, that is, the property $\Delta_{T}$, is just $0.14 \mathrm{~K}$. Similar calculations, involving (Mdci $+\mathrm{R}$ ) data, were carried out for the systems $\mathrm{C} 18+\mathrm{C} 19$ and $\mathrm{C} 20+\mathrm{C} 21$. In the case of the system $\mathrm{C} 18+\mathrm{C} 19$, where $\Delta_{\mathrm{T}}=0.24 \mathrm{~K}$, the calculated two-phase region is somewhat narrower than the experimental data would suggest. The same holds true for C20 + C21, where, however, the difference in width is more outspoken, and $\Delta_{\mathrm{T}}=0.64 \mathrm{~K}$. When taken

(16) Oonk, H. A. J .; Mondieig, D.; Haget; Y.; Cuevas-Diarte, M. A. J . Chem. Phys. 1998, 108 (2), 715.

(17) Mondieig, D.; Espeau, P.; Roblès, L.; Haget, Y.; Oonk, H. A. J.; Cuevas-Diarte, M. A. J . Chem. Soc., Faraday Trans. 1997, 93 (18), 3343.

(18) Rajabalee, F.; Métivaud, V.; Mondieig, D.; Haget, Y.; Oonk, H. A. J. Helv. Chim. Acta 1999, 82 (11), 1916.

(19) Rajabalee, F.; Métivaud, V.; Oonk, H. A. J .; Mondieig, D.; Waldner, P. Phys. Chem. Chem. Phys. 2000, 2, 1345.
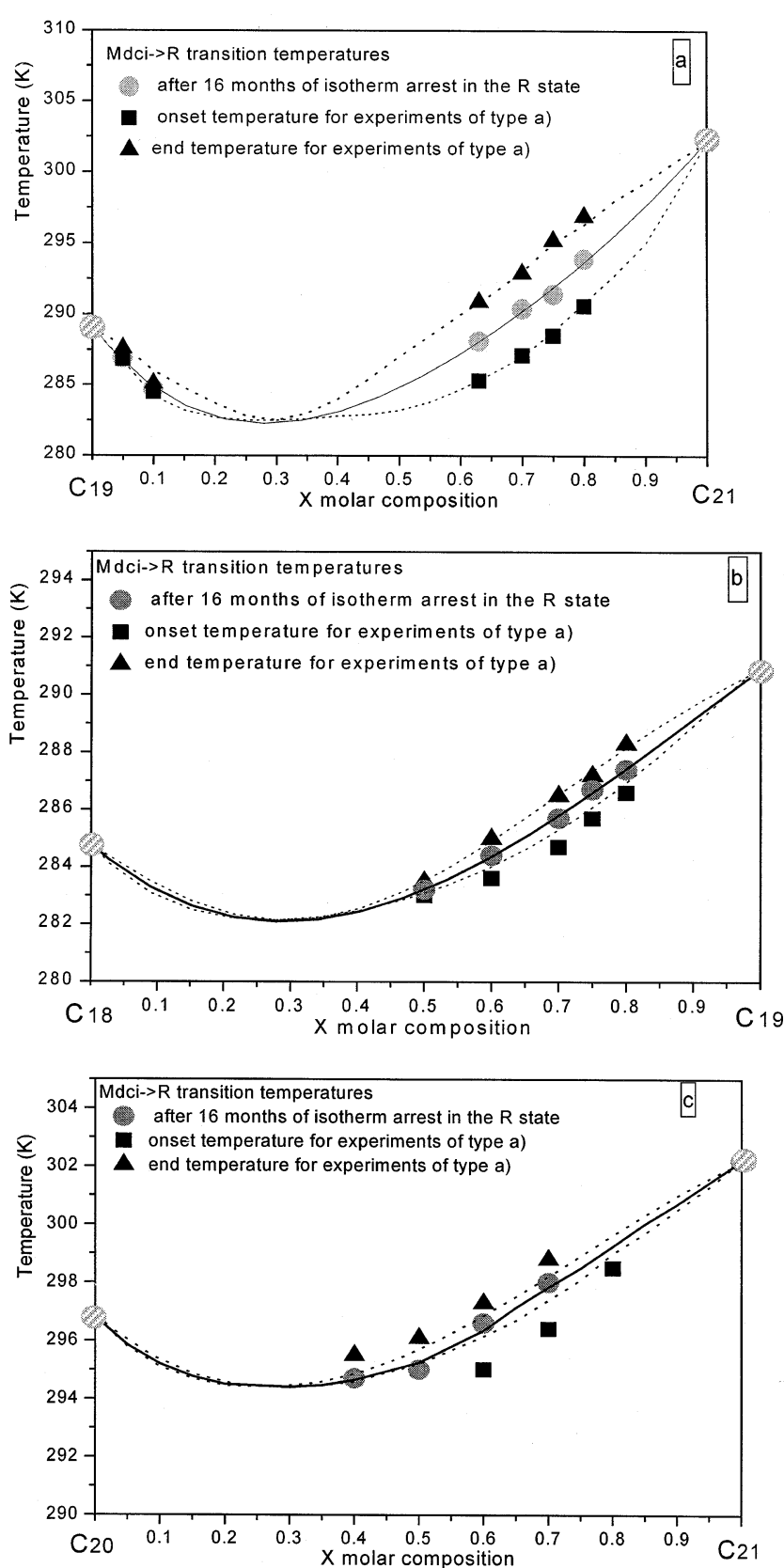

Figure 9. $\mathrm{Mdci} \rightarrow \mathrm{R}$ transition: onset and end temperatures ( $\square$ and $\Delta$, respectively) for mixed samples analyzed immediately after the quench (experiments of type a) and (0) for mixed samples analyzed after 16 months of arrest in the $\mathrm{R}$ state. Dashed lines correspond to the calculated solvi. The partially shaded circle corresponds to the transition of the pure components from the metastable Mdci phase to the R phase.

together, the three systems give rise to a $\Delta_{T}$ value of about $0.3 \mathrm{~K}$. Considering the robust manner of sample preparation, along with the low masses of the samples and the speed of the DSC experiments, one can observe that the disagreement between experimental and calculated results, as expressed by $\Delta_{\mathrm{T}} \approx 0.3 \mathrm{~K}$, is surprisingly low.

To further underpin the significance of the experimental results and their interpretation, we consider the behavior, observed, for the solid to liquid transformation, in the case of the system 1,4-dichlorobenzene + 1,4-dibromobenzene, ${ }^{20} \mathrm{ClCl}+\mathrm{BrBr}$ for short. More precisely, we compared the difference in behavior of samples prepared in a robust manner and samples 
prepared in a meticulous manner. In the robust way mixed crystalline material is prepared by quasi-instantaneous copreci pitation from a solution in an evaporating volatile solvent, such as diethyl ether. In a meticulous way mixed crystalline material is prepared by zone leveling, a procedure which yields some $4 \mathrm{~g}$ of material in about 2 weeks. When studied in a high-speed DSC experiment, the material prepared by zone leveling (ZL) transforms isothermally at the EGC temperature (like the $\Phi_{\text {ord }}$ al kane samples which have been in the R state for a long time). ${ }^{9}$ The material prepared by quasiinstantaneous coprecipitation (QC), on the other hand, displays onset and end temperatures close to the solidus and liquidus temperatures, respectively. When studied by adiabatic calorimetry, which is a procedure by long duration, the behavior of the QC samples is only slightly different from the behavior of the ZL samples: onset of melting on the solidus and end of melting on the liquidus. A fact is that material prepared by zone leveling has a high degree of homogeneity. In previous publications (see, e.g., ref 20), for that matter, we have emphasized that homogeneity is a prerequisite for isothermal transformations. A fact also is that ZL samples are compact, whereas the QC samples are not. The latter are powdery, and the enormous surface enhances molecular mobility-in favor of reaching thermodynamic equilibrium in terms of the equations (7). Likewise, it is not implausible to assume that material prepared by quenching from a melt will have lattice imperfections and voids-again enhancing molecular mobility. As a result, it is plausible to conclude that during the experiments of long duration the material is brought to a state of perfection, characterized by homogeneity and compactness. The molecular mobility needed to reach the state of perfection is offered by the liquid zone, in the case of zone leveling, and found in the rotator state, in the case of the experiments described in this investigation.

In summarizing, an alloy that is kept in the rotator state over a long period of time will become homogeneous and compact. When it is subsequently cooled, in

(20) van der Linde, P. R.; Bolech, M.; den Besten, R.; Verdonk, M. L.; van Miltenburg, J . C.; Oonk, H. A. J . J . Chem. Thermodyn. 2002, 34, 613 . an experiment of short duration, it will, at the $\left[R+\Phi_{\text {ord }}\right]$ EGC, change into the $\Phi_{\text {ord }}$ state. The $\Phi_{\text {ord }}$ form, such as Mdci, which is taken, is the one whose EGC is crossed. When the material is heated, directly after having passed the EGC from R to $\Phi_{\text {ord, }}$, and so in an experiment of short duration, it will change from $\Phi_{\text {ord }}$ to $R$, in an isothermal manner. If, on passing the EGC from $R$ to $\Phi_{\text {ord, }}$ the alloy "enters into" a $\left[\Phi_{\text {ord }}+\Phi^{\prime}\right.$ ord $]$ two-phase region, it will, when kept there over a long period of time, split up very slowly into $\Phi_{\text {ord }}$ and $\Phi_{\text {ord. }}^{\prime}$.

\section{Conclusions}

We show here the importance of the influence of thermal history on the behavior of mixed materials. In the case of n-alkane mixed samples, we observed that the onset and end temperatures of the $\Phi_{\text {ord }}$ to rotator state transition vary with the duration of the arrest in the $\mathrm{R}$ state. The temperature width of the transition decreases with duration of arrest. It is possible to make mixed samples to change isothermally from the $\Phi_{\text {ord }}$ to the rotator state. Isothermal $\Phi_{\text {ord }} \rightarrow \mathrm{R}$ transitions have been observed for all compositions in C18 + C19, C19 $+\mathrm{C} 20, \mathrm{C} 19+\mathrm{C} 21, \mathrm{C} 20+\mathrm{C} 21$, and C23 + C25, by keeping mixed samples for a long time in the rotator state before studying the $\Phi_{\text {ord }} \rightarrow R$ transition.

The isothermal transition curves $\mathrm{T}(\mathrm{x})$ correspond to the EGC (equal G curves) of the two phases. We show that the EGC experimental data can be used for a thermodynamic analysis of the change from $\Phi_{\text {ord }}$ to $R$ and that the calculated results (lower solvus and upper solvus temperatures of the $\left[\Phi_{\text {ord }}+R\right]$ equilibrium) are in good agreement with the onset and end temperatures, obtained by DSC experiments, on samples which had not been kept for a long time in the R state.

The thermodynamic interpretation of the isothermal temperatures and the X-ray diffraction observations show that the isothermal phenomenon in alkane alloys is similar to diffusionless, or martensitic, transformations in metal alloys.

Supporting Information Available: Figure showing the calculation for the Mdci phase in the C19 + C20 system (PDF). This material is available free of charge via the Internet at http://pubs.acs.org.

CM0213624 